\title{
Comparison of Different Phase-Shift Control Methods at Isolated Bidirectional DC-DC Converter
}

\author{
R. Ilker Kayaalp"1 , Tugce Demirdelen ${ }^{1}$, Tahsin Koroglu ${ }^{1}$, M. Ugras Cuma ${ }^{1}$, K. Cagatay Bayindir ${ }^{2}$, \\ Mehmet Tumay 1
}

Accepted $22^{\text {th }}$ November 2015

DOI: 10.18100/ijamec.60506

\begin{abstract}
In this study, the operation, design and comparison of single, extended and dual phase shift control methods on bidirectional DCDC converters are discussed. The major components (DC link capacitors and inductors) are derived for different phase shifting methods in order to obtain maximum efficiency. Triggering signals, voltages and current waveforms are compared for buck-boost conditions through PSCAD simulation results on the single-phase full-bridge converter topology with isolation transformer.
\end{abstract}

Keywords: Bidirectional DC-DC Converters, Buck-Boost, Phase-Shift Control, Single, Extended, Dual, Modelling, Comparison, Efficiency

\section{Introduction}

Bidirectional DC-DC Converters (BDCs) are used for increasing, decreasing or multiplexing a voltage that is took from DC supplies in order to obtain stable or variable DC voltages. For this reason, especially nowadays, BDCs are very common at power electronics and industrial many electronic applications such as transportation vehicles industry, portable electronic equipments, renewable energy systems and small dimensions that need to be fit. Thanks to these features, BDCs reduce cost and increase efficiency for improving performance of the power electronic systems.

In recent years, a lot of topics have been worked by many scientists for improving system efficiency on the BDCs and these studies are generally about phase shift control methods and their different variations. In literature, the most commonly used control method is single phase shift method [1 - 5] among phase shift control methods. Moreover, there are several comparison articles about Single (Traditional) Phase Shift (SPS), Extended Phase Shift (EPS) and Dual Phase Shift (DPS) in [6 - 10]. However, various topologies are improved that are used in several applications, isolated BDCs are usually based on single-phase, full-bridge topology. Therefore, these PI based phase shift control methods are applied to single-phase, full-bridge topology with isolation transformer.

In this paper, the aim of this study is to obtain and observe of differences at phase shift control methods by using $20 \mathrm{kHz} / 1: 1$ isolation transformer. The operation principles of the system play an important role to improve efficiency of BDC topologies in available literature. Thus, three different phase shift control methods are applied to full bridge isolated BDC topology by creating triangular signals, and simulation results show that the most efficient controller method is DPS, EPS and SPS, respectively. These results show the validity of theoretical analysis.

\footnotetext{
${ }^{1}$ Çukurova University Department of Electrical and Electronics Engineering Adana, TURKEY

${ }^{2}$ Ylldırım Beyazıt University, Department of Energy Systems Engineering, Ulus, Ankara/TURKEY

*Corresponding Author: Email: ikayaalp@cu.edu.tr
}

\section{Modelling and Controller}

\subsection{Bidirectional DC-DC Converter Topology}

The proposed converter is shown in Fig. 1 and it is designed as [11, $12]$.

Single-Phase Full-Bridge Bidirectional Isolated Buck-Boost DC-DC Converter

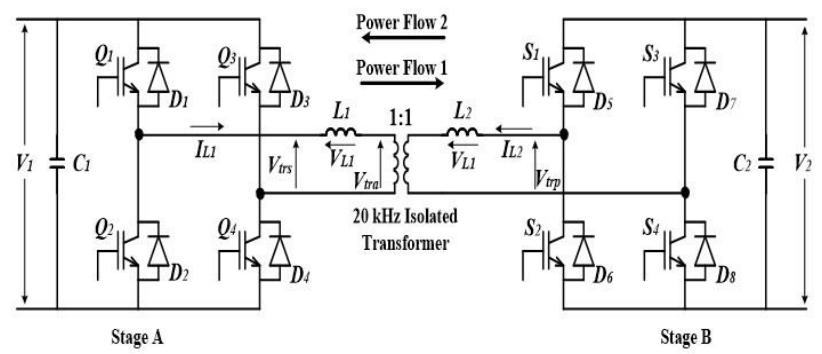

Figure 1. Circuit Topology of Single-Phase Full-Bridge Bidirectiona Isolated Buck-Boost DC-DC Converter

In this $15 \mathrm{~kW}$ converter model, efficiencies of phase-shift control methods are calculated by without using snubber capacitors in order to clearly understand of which control method is better than the others. Because these capacitors have positive effect $(50 \%)$ on efficiency of the converter. Additionally, two dc-link capacitors are used for limiting of inrush current and achieving to zero voltage switching (ZVS). This application cause to hardswitching. Thus, this converter is also called dual active bridge passive-clamp circuit. Converter is operated by power flow 1 and power flow 2 and comparison of phase shift methods are performed both of the two directions.

Auxiliary inductors and dc-link capacitors are calculated according to buck and boost phase-shift angles of SPS, but capacitor values can be reduced if the system is operated by EPS and DPS respectively.

$$
\begin{aligned}
& P=\frac{V_{1} V_{2} N}{\omega L}\left(\delta-\frac{\delta^{2}}{\pi}\right) \\
& C_{\text {input }}=\frac{\Delta I_{L} T_{s w}}{8 \Delta V_{O}} \\
& C_{\text {output }}=\frac{I_{O} D T_{s w}}{\Delta V_{O}}
\end{aligned}
$$


In equation (2.1) should be $V_{2}>V_{1}$ and single phase shift angle $\delta$ is used for calculating auxiliary inductances $L_{1}$ and $L_{2}$ ( $L=L_{\text {trans }}+2 L_{1}$ or $L=L_{\text {trans }}+2 L_{2}, L_{\text {trans }}$ is the inductance of high frequency transformer) based on power of the converter $P$, turn ratio $N$ and $\omega=2 \pi f$ by considering buck and boost modes [11].

Equation (2.2) and (2.3) provide to calculate dc-link capacitors. Where $\Delta V_{o}$ is peak-to-peak voltage ripple of the buck mode of the converter output ( 1 to $2 \%$ of the output voltage) for (2.2) and $f$ is switching frequency, $T_{s w}$ is $1 / f$. Moreover, $\Delta I_{L}$ is the peak-to-peak current ripple. At equation (2.3), $\mathrm{D}$ is duty cycle and $\Delta V_{o}$ is peakto-peak voltage ripple of the boost mode of the converter output. Other parameters are the same as equation (2.2).

The converter and simulation parameters are shown at Table 1 and Table 2.

Table 1. Circuit Parameters of The DC-DC Converter for Buck Mode

\begin{tabular}{|c|c|c|c|c|}
\hline \multicolumn{2}{|c|}{ Control Methods } & SPS & EPS & DPS \\
\hline Rated DC Voltages & $V_{l}, V_{2}$ & $\begin{array}{c}200 \mathrm{~V}, \\
160 \mathrm{~V}\end{array}$ & $\begin{array}{c}200 \mathrm{~V}, \\
160 \mathrm{~V}\end{array}$ & $\begin{array}{c}200 \mathrm{~V}, \\
160 \mathrm{~V}\end{array}$ \\
\hline DC-Link Capacitors & $C_{l}, C_{2}$ & $\begin{array}{c}70 \mathrm{mF}, \\
180 \mathrm{mF}\end{array}$ & $\begin{array}{c}56 \mathrm{mF}, \\
144 \mathrm{mF}\end{array}$ & $\begin{array}{c}46 \mathrm{mF}, \\
120 \mathrm{mF}\end{array}$ \\
\hline Auxilary Inductors & $L_{l}, L_{2}$ & $\begin{array}{c}18 \mu \mathrm{H}, \\
12 \mu \mathrm{H}\end{array}$ & $\begin{array}{c}18 \mu \mathrm{H}, \\
12 \mu \mathrm{H}\end{array}$ & $\begin{array}{c}18 \mu \mathrm{H}, \\
12 \mu \mathrm{H}\end{array}$ \\
\hline $\begin{array}{c}\text { Transformer Turn } \\
\text { Ratio }\end{array}$ & $N$ & $1: 1$ & $1: 1$ & $1: 1$ \\
\hline Switching Frequency & $f$ & $20 \mathrm{kHz}$ & $20 \mathrm{kHz}$ & $20 \mathrm{kHz}$ \\
\hline
\end{tabular}

Table 2. Circuit Parameters of The DC-DC Converter for Boost Mode

\begin{tabular}{|c|c|c|c|c|}
\hline \multicolumn{2}{|c|}{ Control Methods } & SPS & EPS & DPS \\
\hline Rated DC Voltages & $V_{l}, V_{2}$ & $\begin{array}{c}100 \mathrm{~V}, \\
160 \mathrm{~V}\end{array}$ & $\begin{array}{c}100 \mathrm{~V}, \\
160 \mathrm{~V}\end{array}$ & $\begin{array}{c}100 \mathrm{~V}, \\
160 \mathrm{~V}\end{array}$ \\
\hline DC-Link Capacitors & $C_{l}, C_{2}$ & $\begin{array}{c}180 \mathrm{mF}, \\
70 \mathrm{mF}\end{array}$ & $\begin{array}{c}144 \mathrm{mF}, \\
56 \mathrm{mF}\end{array}$ & $\begin{array}{c}120 \mathrm{mF}, \\
46 \mathrm{mF}\end{array}$ \\
\hline Auxilary Inductors & $L_{l}, L_{2}$ & $\begin{array}{c}12 \mu \mathrm{H}, \\
18 \mu \mathrm{H}\end{array}$ & $\begin{array}{c}12 \mu \mathrm{H}, \\
18 \mu \mathrm{H}\end{array}$ & $\begin{array}{c}12 \mu \mathrm{H}, \\
18 \mu \mathrm{H}\end{array}$ \\
\hline $\begin{array}{c}\text { Transformer Turn } \\
\text { Ratio }\end{array}$ & $N$ & $1: 1$ & $1: 1$ & $1: 1$ \\
\hline Switching Frequency & $f$ & $20 \mathrm{kHz}$ & $20 \mathrm{kHz}$ & $20 \mathrm{kHz}$ \\
\hline
\end{tabular}

The rated DC voltage values are selected close to each other. Its reason is not only improving the converter performance at these voltages but also defining suitable operating range between dynamic voltage restorer (DVR) and shunt hybrid active power filter (SHAPF) at unified power quality conditioner (UPQC) systems.

\subsection{Phase-Shift Control Methods}

\subsubsection{Single Phase Shift Control (SPS):}

SPS is conventional control method and it is the most widely used control method in researches. Because, its theoretical and experimental analysis are simple.

Triggering signals are defined by creating $\delta$ between Stage A (Q switches) and Stage B (S switches). It provides SPS control at Fig. 1. Also Fig. 2 and Fig. 3 show the phase shift angles between rated voltages against inductor current waveforms. Where, period is $T=t_{1}+t_{2}+t_{3}+t_{4}+t_{5}+t_{6}$.

Moreover, Table 3 gives switching states (ON conditions) of SPS control.

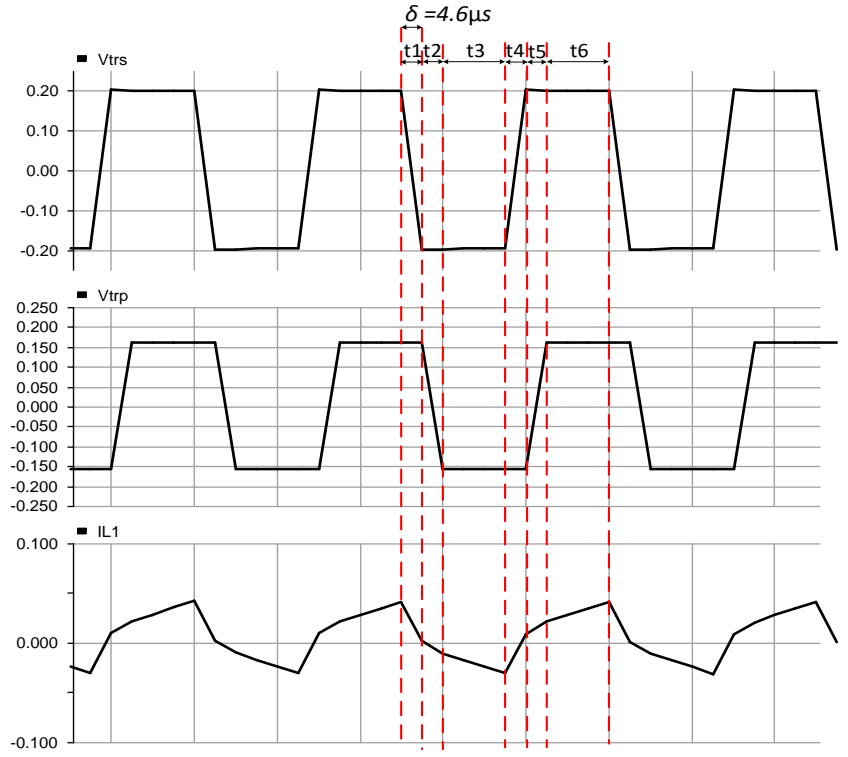

Figure 2. Phase shift angle of Buck Mode at SPS Control, Power Flow 1.

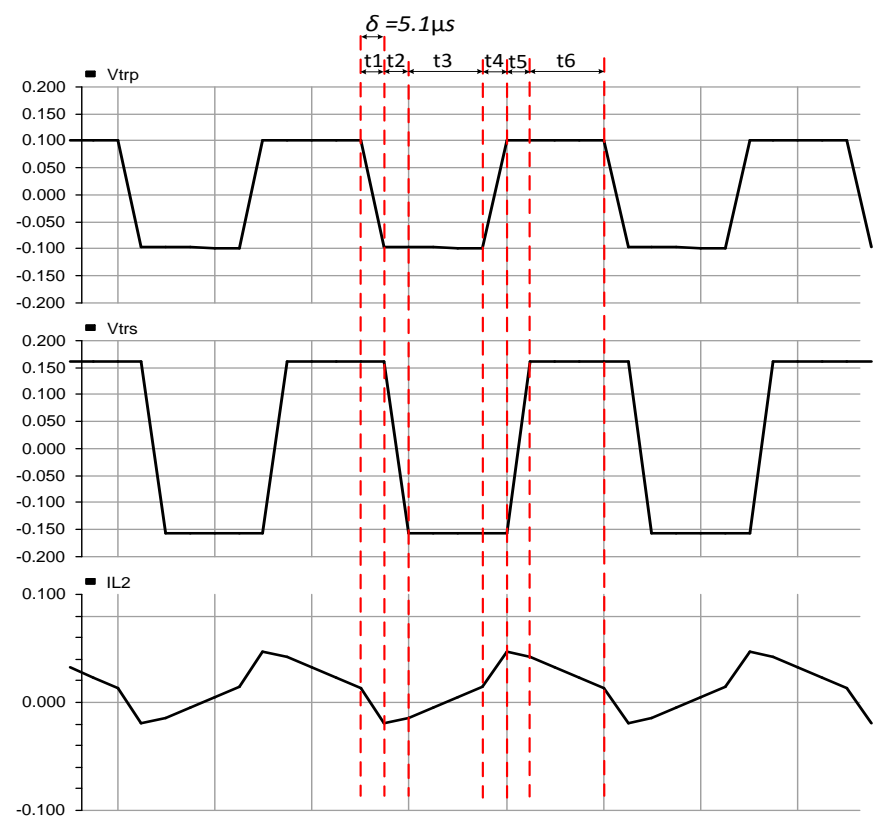

Figure 3. Phase shift angle of Boost Mode at SPS Control, Power Flow 2.

Table 3. Switching States of Buck Mode SPS Control for Power Flow 1.

\begin{tabular}{|c|c|c|c|c|c|}
\hline $\boldsymbol{t}_{\boldsymbol{1}}$ & $\boldsymbol{t}_{\mathbf{2}}$ & $\boldsymbol{t}_{\mathbf{3}}$ & $\boldsymbol{t}_{\boldsymbol{4}}$ & $\boldsymbol{t}_{\mathbf{5}}$ & $\boldsymbol{t}_{\boldsymbol{6}}$ \\
\hline $\mathrm{D}_{3}, \mathrm{D}_{2}$ & $\mathrm{Q}_{3}, \mathrm{Q}_{2}$ & $\mathrm{Q}_{3}, \mathrm{Q}_{2}$ & $\mathrm{D}_{1}, \mathrm{D}_{4}$ & $\mathrm{Q}_{1}, \mathrm{Q}_{4}$ & $\mathrm{Q}_{1}, \mathrm{Q}_{4}$ \\
$\mathrm{D}_{5}, \mathrm{D}_{8}$ & $\mathrm{~S}_{1}, \mathrm{~S}_{4}$ & $\mathrm{D}_{6}, \mathrm{D}_{7}$ & $\mathrm{D}_{6}, \mathrm{D}_{7}$ & $\mathrm{~S}_{2}, \mathrm{~S}_{3}$ & $\mathrm{D}_{5}, \mathrm{D}_{8}$ \\
\hline
\end{tabular}

\subsubsection{Extended Phase Shift Control (EPS):}

Compared with SPS, EPS can greatly improve efficiency. It reduces current stress and backflow power considerably. Thus, it gives good results even it works wide input and output voltage ranges under light and medium loads. Also its implementation is harder than SPS, but easier than DPS.

In EPS control, $\mathrm{Q}_{1}-\mathrm{Q}_{2}, \mathrm{Q}_{3}-\mathrm{Q}_{4}, \mathrm{~S}_{1}-\mathrm{S}_{2}-\mathrm{S}_{3}-\mathrm{S}_{4}$ switches have different phase angles. Fig. 4 and Fig. 5 demonstrate simulated waveforms of the rated voltages and inductors current.

Where, period is $T=t_{1}+t_{2}+t_{3}+t_{4}+t_{5}+t_{6}$ and Table 4 gives the switching states (ON conditions) of EPS control. 


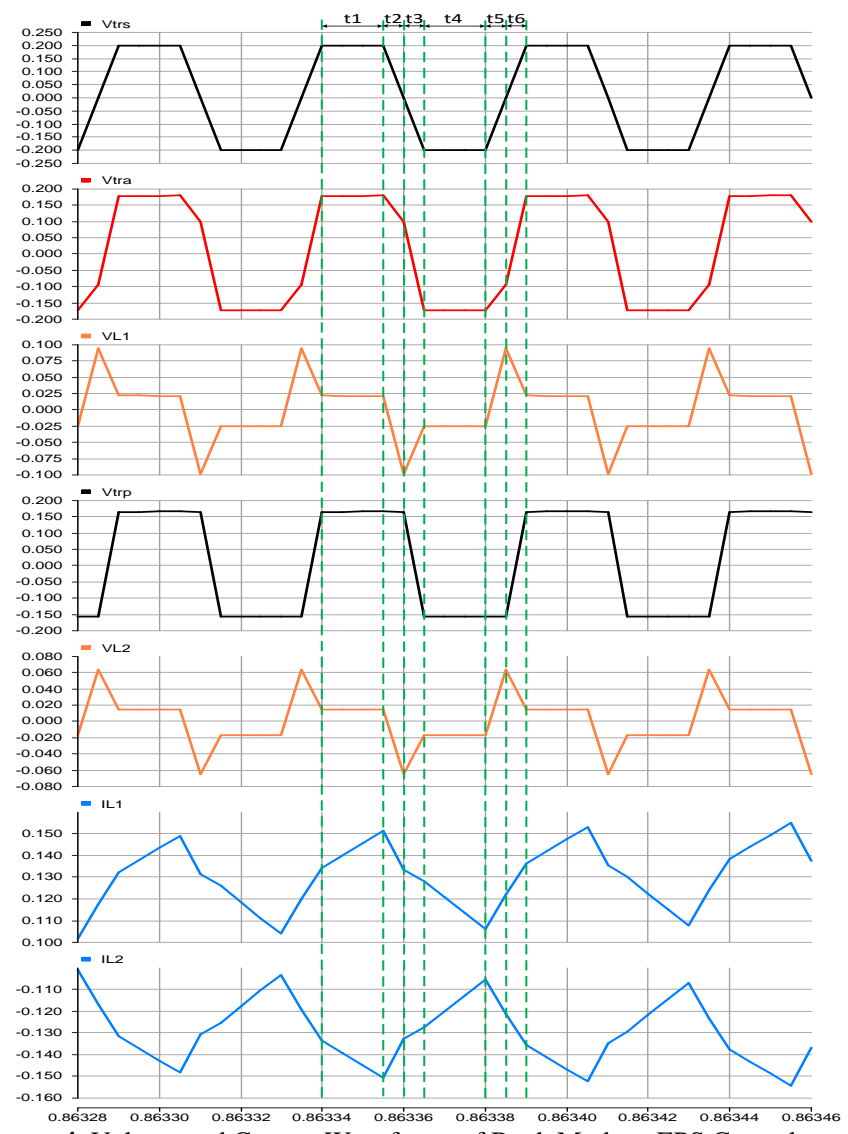

Figure 4. Voltage and Current Waveforms of Buck Mode at EPS Control, Power Flow 1.

Table 4. Switching States of Buck Mode EPS Control for Power Flow 1.

\begin{tabular}{|c|c|c|c|c|c|}
\hline $\boldsymbol{t}_{\boldsymbol{1}}$ & $\boldsymbol{t}_{\mathbf{2}}$ & $\boldsymbol{t}_{3}$ & $\boldsymbol{t}_{\mathbf{4}}$ & $\boldsymbol{t}_{\mathbf{5}}$ & $\boldsymbol{t}_{\mathbf{6}}$ \\
\hline $\mathrm{D}_{2}, \mathrm{Q}_{4}$ & $\mathrm{Q}_{2}, \mathrm{D}_{4}$ & $\mathrm{Q}_{2}, \mathrm{Q}_{3}$ & $\mathrm{D}_{1}, \mathrm{Q}_{3}$ & $\mathrm{Q}_{1}, \mathrm{D}_{3}$ & $\mathrm{Q}_{1}, \mathrm{Q}_{4}$ \\
$\mathrm{D}_{5}, \mathrm{D}_{8}$ & $\mathrm{~S}_{1}, \mathrm{~S}_{4}$ & $\mathrm{D}_{6}, \mathrm{D}_{7}$ & $\mathrm{D}_{6}, \mathrm{D}_{7}$ & $\mathrm{~S}_{2}, \mathrm{~S}_{3}$ & $\mathrm{D}_{5}, \mathrm{D}_{8}$ \\
\hline
\end{tabular}

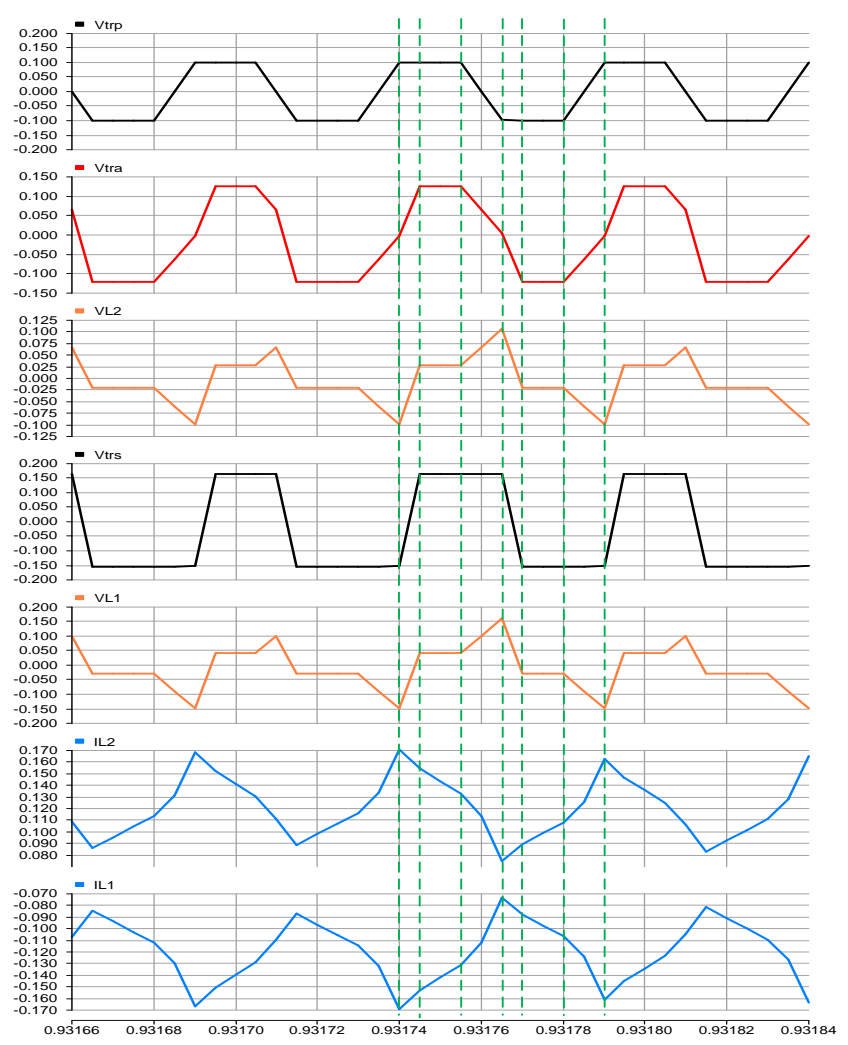

Figure 5. Voltage and Current Waveforms of Boost Mode at EPS Control, Power Flow 2.

\subsubsection{Dual Phase Shift Control (DPS):}

When the voltage range of two side of the transformer increase, the current stress becomes higher values. This condition gives rise to use higher volt-ampere rating components. In order to minimize the weight and size, switching frequency must be increase. Under this condition, increase of the current stress cause to switching losses and great reduction in efficiency. Therefore, requirement of good performance, DPS control method must be use instead of increasing switching frequency. DPS control has complex calculation and its modelling is harder than the SPS and EPS. If it is taken dead band effects into consideration, the complexity of DPS control would have risen.

All of the switching legs have different phase shift angles at DPS control method. In other words, Q1-Q2, Q3-Q4, S1-S2, S3S4 switches have different angles each other. Fig. 6 and Fig. 7 also present rated voltages against inductors current waveform for buck and boost modes.

Where, period is $T=t_{1}+t_{2}+t_{3}+t_{4}+t_{5}+t_{6}+t_{7}+t_{8}$ at Fig. 6 . Moreover, Table 5 gives the buck mode switching states (ON-OFF conditions) of DPS control at single phase full bridge dual active BDC topology.

Table 5. Switching States of Buck Mode DPS Control for Power Flow 1.

\begin{tabular}{|c|c|c|c|c|c|c|c|c|}
\hline time & $\boldsymbol{t}_{\boldsymbol{1}}$ & $\boldsymbol{t}_{\mathbf{2}}$ & $\boldsymbol{t}_{3}$ & $\boldsymbol{t}_{\boldsymbol{4}}$ & $\boldsymbol{t}_{\boldsymbol{5}}$ & $\boldsymbol{t}_{\boldsymbol{6}}$ & $\boldsymbol{t}_{7}$ & $\boldsymbol{t}_{\boldsymbol{8}}$ \\
\hline $\mathbf{O N}$ & $\mathrm{Q}_{3}$ & $\mathrm{Q}_{2}$ & $\mathrm{~S}_{3}$ & $\mathrm{~S}_{2}$ & $\mathrm{Q}_{4}$ & $\mathrm{Q}_{1}$ & $\mathrm{~S}_{4}$ & $\mathrm{~S}_{1}$ \\
\hline $\mathbf{O F F}$ & $\mathrm{S}_{2}$ & $\mathrm{Q}_{1}$ & $\mathrm{~S}_{4}$ & $\mathrm{~S}_{1}$ & $\mathrm{Q}_{3}$ & $\mathrm{Q}_{2}$ & $\mathrm{~S}_{3}$ & $\mathrm{~S}_{2}$ \\
\hline
\end{tabular}

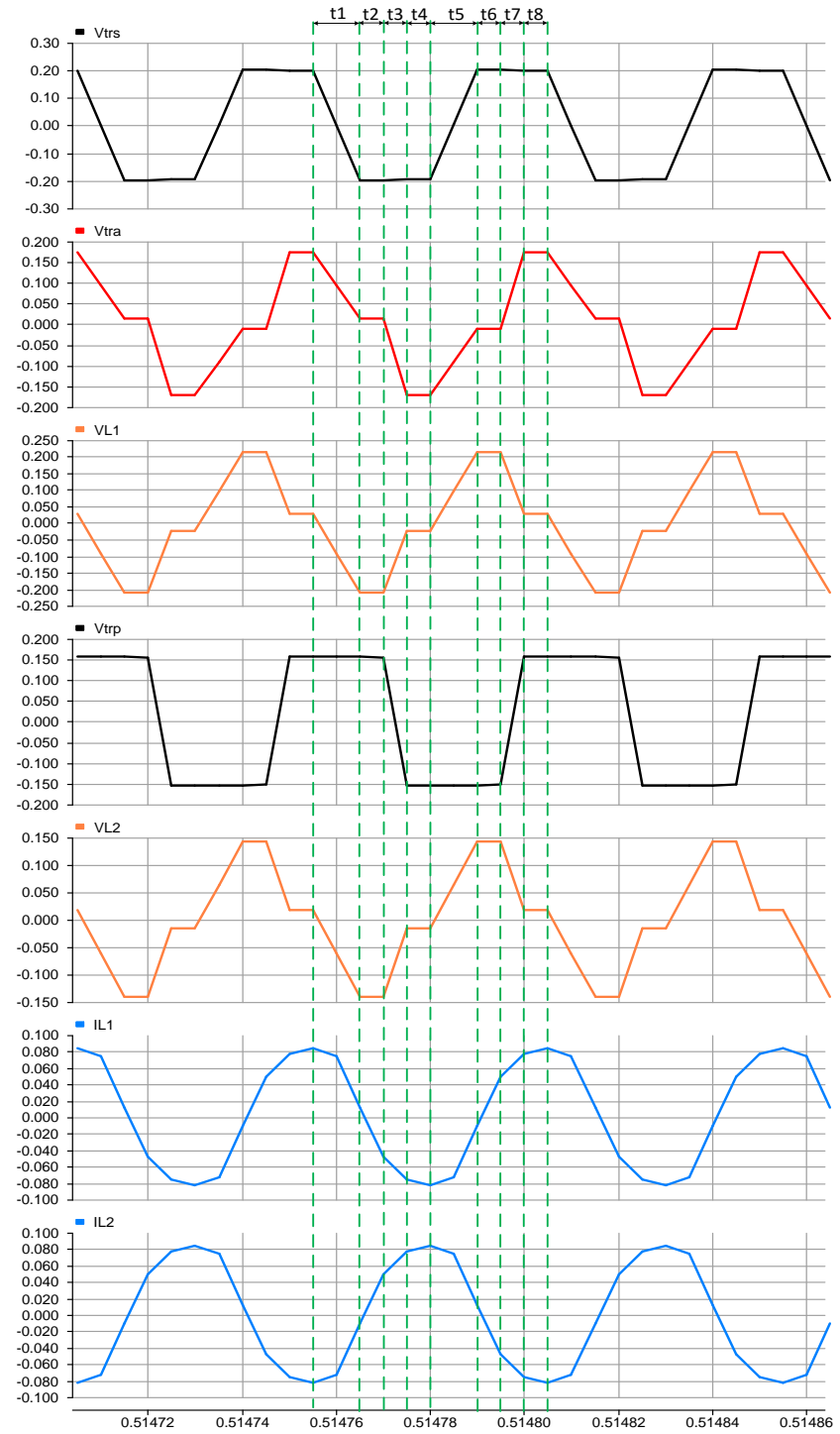

Figure 6. Voltage and Current Waveforms of Buck Mode at DPS Control, Power Flow 2 


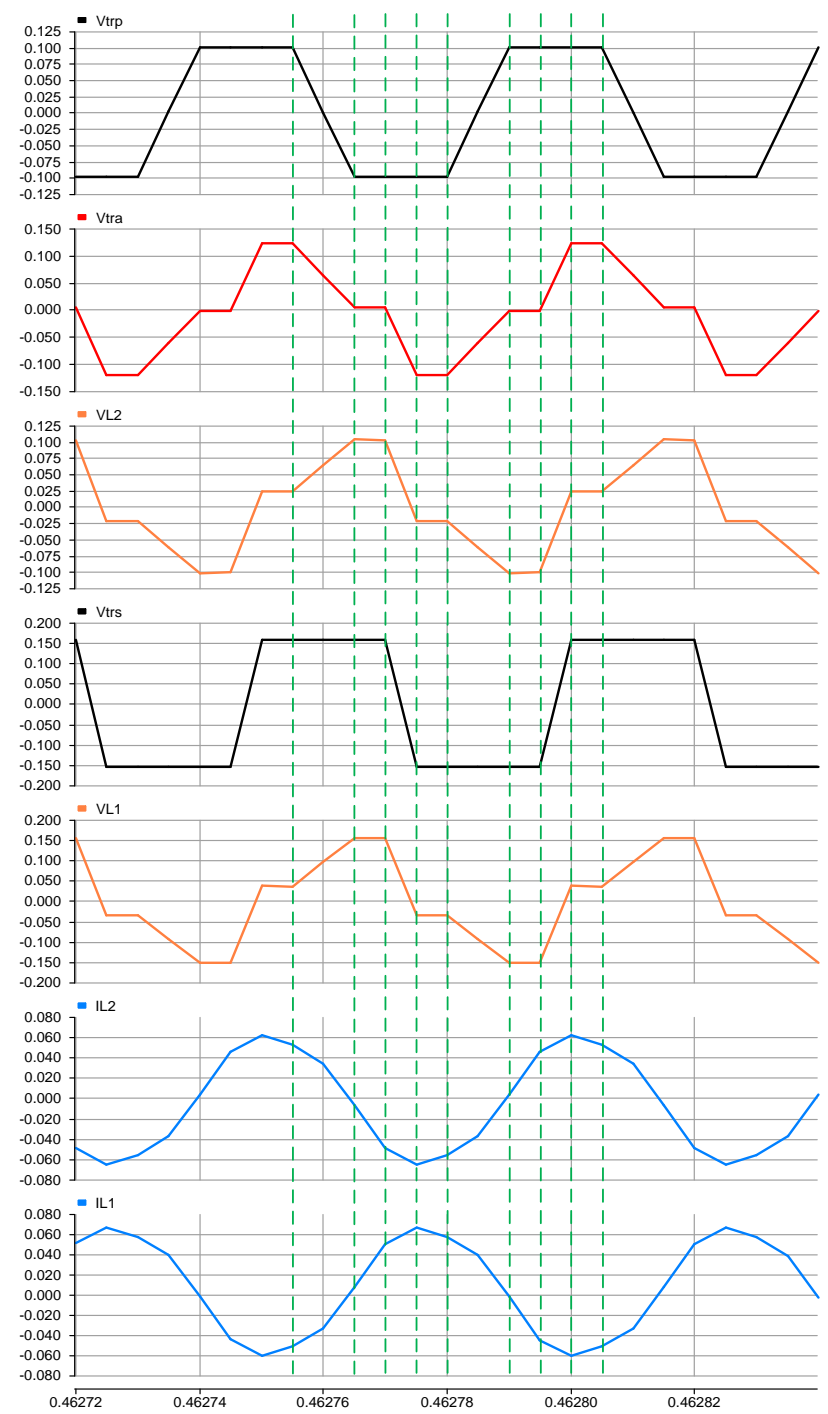

Figure 7. Voltage and Current Waveforms of Buck Mode at DPS Control, Power Flow 2.

\subsubsection{Triggering Signals of Control Methods}

Fig. 8, Fig. 9 and Fig. 10 demonstrates triangular triggering gate signals of IGBTs with 50\% duty cycle ratio for SPS, EPS and DPS respectively. Phase shift angles of triggering signals are based on PI calculation in controller system algorithm.

For SPS control method, phase shift angle $(\delta)$ can be calculated by using equation (2.1). But phase shift angle of EPS can be calculated by using equation (2.4).

At Fig. $4, V_{t r s}$ is a three level voltage and it has the same rising edge with $V_{\text {tra. }} D$ is defined as high level ratio of the three-level pulse width modulation (PWM) voltage waveform, based on the basic analysis [9] where;

$$
\mathrm{O} \leq \boldsymbol{D} \leq 1, \delta=\pi-D \pi(2.4) \text { and } D T=t_{1}+t_{2}+t_{3}+t_{5}+t_{6} \text { or }
$$

$D T=T-t_{4}$

For calculating phase shift angles of DPS control, two conditions should be analysed based on the same way with [8]:

$$
0 \leq D_{1} \leq D_{2} \leq 1 \text { and }
$$

$0 \leq D_{2}<D_{1} \leq 1$

Where $D_{1}$ and $D_{2}$ are the inner and outer phase shift ratios, respectively. $T_{h s}$ is the half switching period and $V_{t r s}$ and $V_{t r p}$ are the ac output voltages of Stage A and Stage B.

From Fig. 6:

$D_{l} T_{h s}=t_{1}$ or $D_{1} T_{h s}=t_{5}$ and $D_{2} T_{h s}=t_{6}+t_{7}$

(2.5) and (2.6)
The average transmission power and the current stress of IBDC with DPS control can be presented as:

$$
\begin{aligned}
& P=\frac{1}{T_{h s}} \int_{0}^{T_{h s}} V_{t r s} I_{L}(t) d t \\
& i_{\max }=\max \left\{\left|I_{L}(t)\right|\right\}
\end{aligned}
$$

The voltage conversion ratio is defined as $k=V_{l} / N V_{2}$ and $k$ is assumed $k \leq 1$. For the other condition, $k<1$. Based on the basic analysis [13], [14], [15] the average transmission power and current stress of IBDC with DPS control are derived as:

If $0 \leq D_{1} \leq D_{2} \leq 1$

$$
\begin{aligned}
& P=\frac{N V_{1} V_{2}}{2 f_{s} L}\left[D_{2}\left(1-D_{2}\right)-\frac{1}{2} D_{1}^{2}\right] \\
& \text { If } 0 \leq D_{2}<D_{1} \leq 1 \text {; } \\
& P=\frac{N V_{1} V_{2}}{2 f_{s} L} D_{2}\left(1-D_{1}-\frac{1}{2} D_{2}\right) \\
& i_{\text {max }}=\left|I_{L}\left(t_{0}\right)\right|=\frac{N V_{2}}{4 f_{s} L}\left[(k-1)\left(1-D_{1}\right)+2 D_{2}\right]
\end{aligned}
$$

Where $f_{s}$ is the switching frequency and $\mathrm{L}$ is the sum of transformer leakage inductance and auxiliary inductor $\mathrm{L}_{1}$. Additionally, when the load is set as resistance $\mathrm{R}$, from (2.7) it can be derived;

If $0 \leq D_{1} \leq D_{2} \leq 1$;

$$
\begin{aligned}
P & =\frac{N V_{1} R}{2 f_{s} L}\left[D_{2}\left(1-D_{2}\right)-\frac{1}{2} D_{1}^{2}\right] \\
\text { If } 0 & \leq D_{2}<D_{1} \leq 1 ; \\
P & =\frac{N V_{1} R}{2 f_{s} L} D_{2}\left(1-D_{1}-\frac{1}{2} D_{2}\right)
\end{aligned}
$$

Similarly, it can be also calculated phase shift angle of SPS control method by using phase shift ratio $D[16]$ and it can be expressed as;

$$
\begin{aligned}
& P=\frac{N V_{1} R}{2 f_{s} L} D(1-D) \\
& i_{T \max }=\frac{N V_{2}}{4 f_{s} L}(k-1+2 D) \\
& V_{2}=\frac{N V_{1} R}{2 f_{s} L} D(1-D)
\end{aligned}
$$

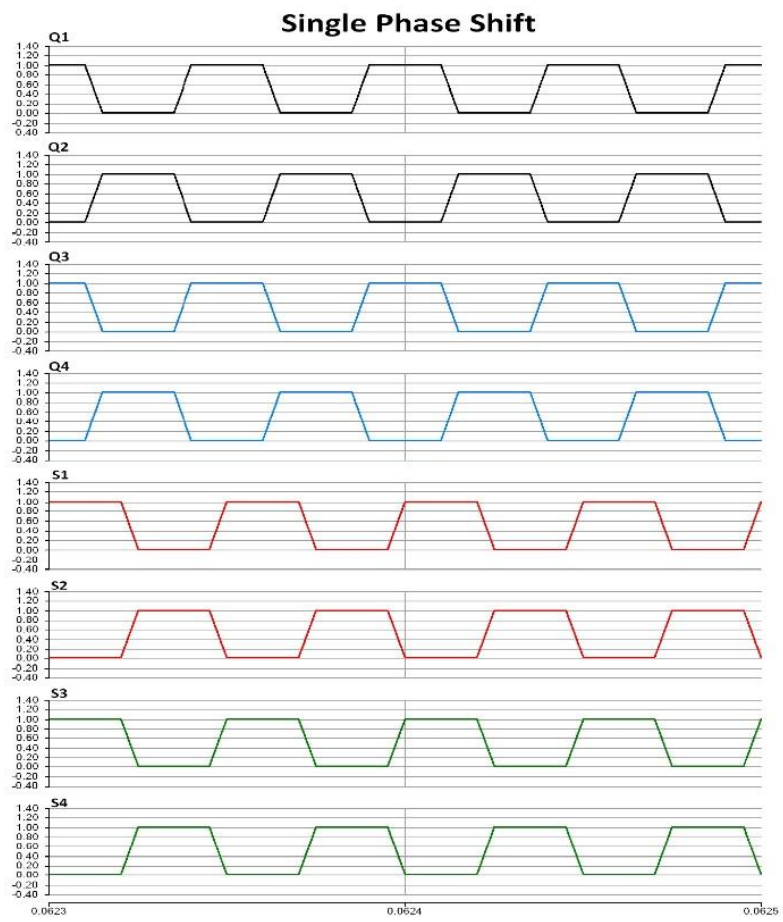

Figure 8. Triggering gate signals of SPS control method 


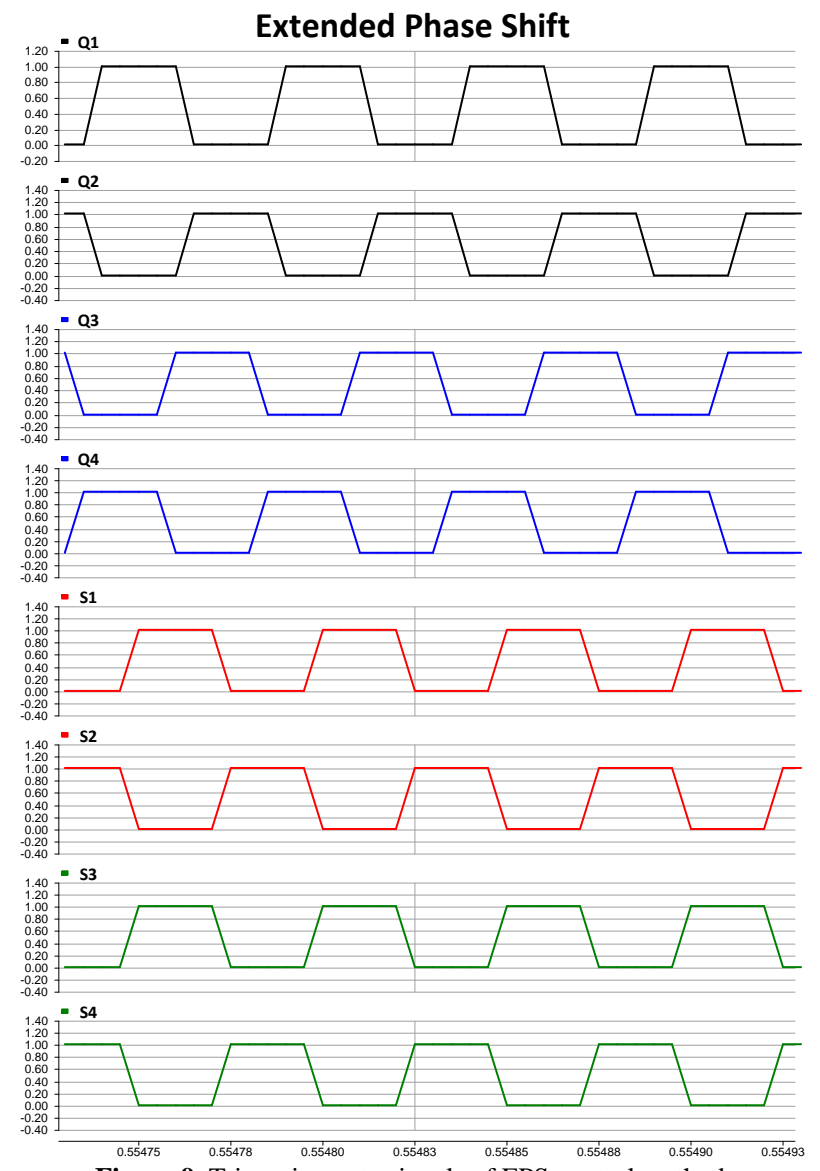

Figure 9. Triggering gate signals of EPS control method

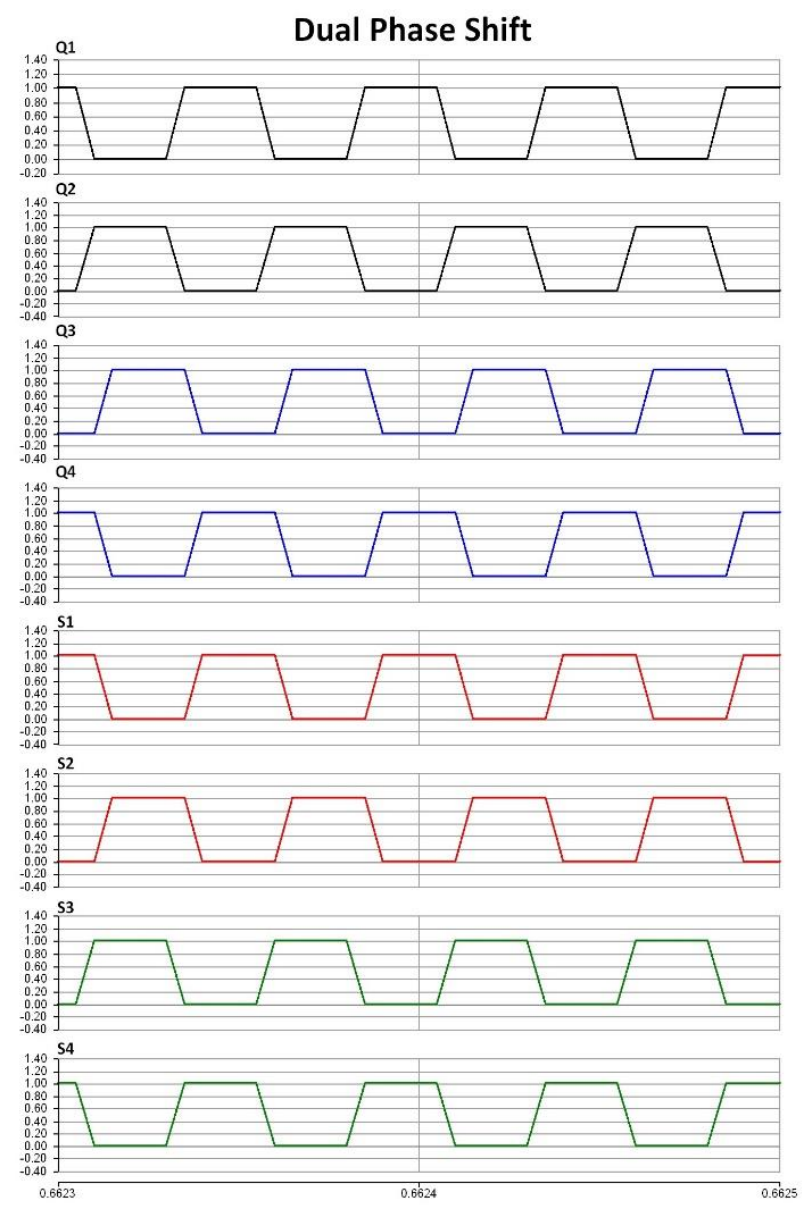

Figure 10. Triggering gate signals of DPS control method

\section{Comparison of Efficiencies}

\subsection{Efficiency Analysis of Phase Shift Control Methods}

When the investigating of power waveforms at control methods. It can be obtained input and output power of the IBDC. After the simulated power waveforms, efficiencies can be calculated by using equation (3.1)

$$
\eta=\frac{P_{\text {in }}-\left(P_{\text {in }}-P_{\text {out }}\right)}{P_{\text {in }}} \times 100=\frac{P_{\text {in }}-P_{\text {totalloss }}}{P_{\text {in }}} \times 100
$$

$\eta$ is efficiency, $P_{\text {in }}$ is input power, $P_{\text {out }}$ is output power and $P_{\text {totalloss }}$ contains all of the switching and conduction losses. Input-output power waveforms are shown at Table 6, Table 7 and Table 8 for SPS, EPS and DPS buck and boost conditions respectively. $P_{l}$ is input power and $P_{2}$ is output power at Table 6,7 and 8 .

Table 6. Input-Output Power Waveforms of SPS for Buck \& Boost Modes.

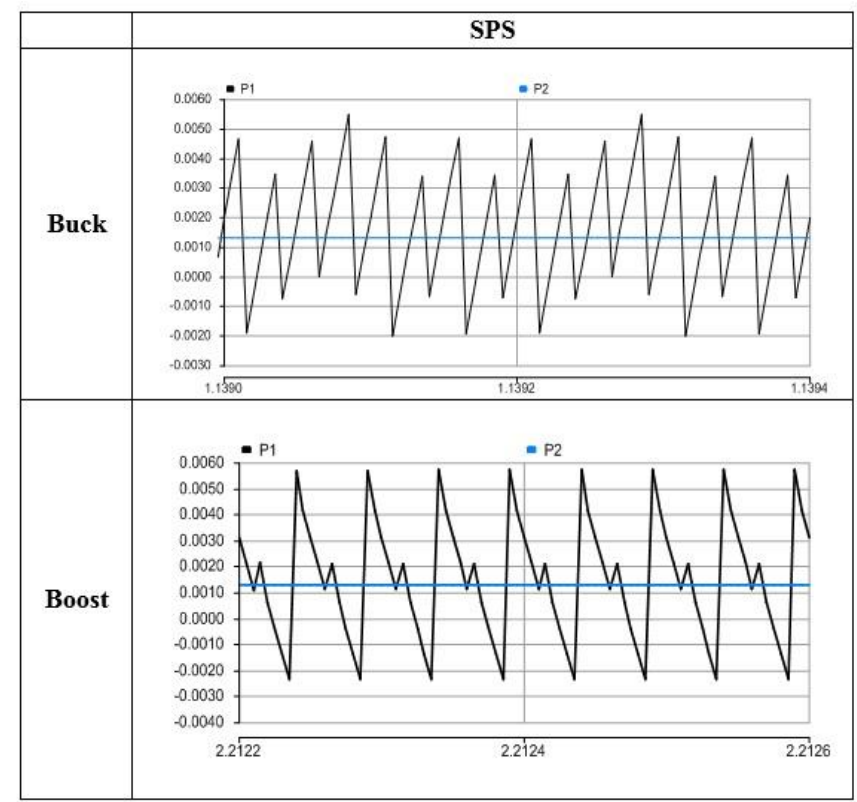

Table 7. Input-Output Power Waveforms of EPS for Buck \& Boost Modes.

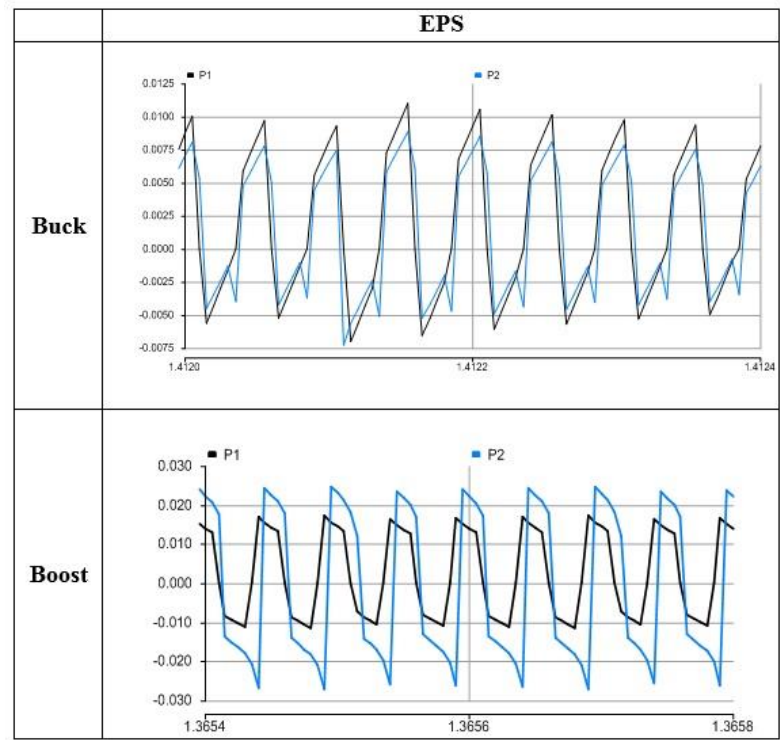


Table 8. Input-Output Power Waveforms of DPS for Buck \& Boost Modes.

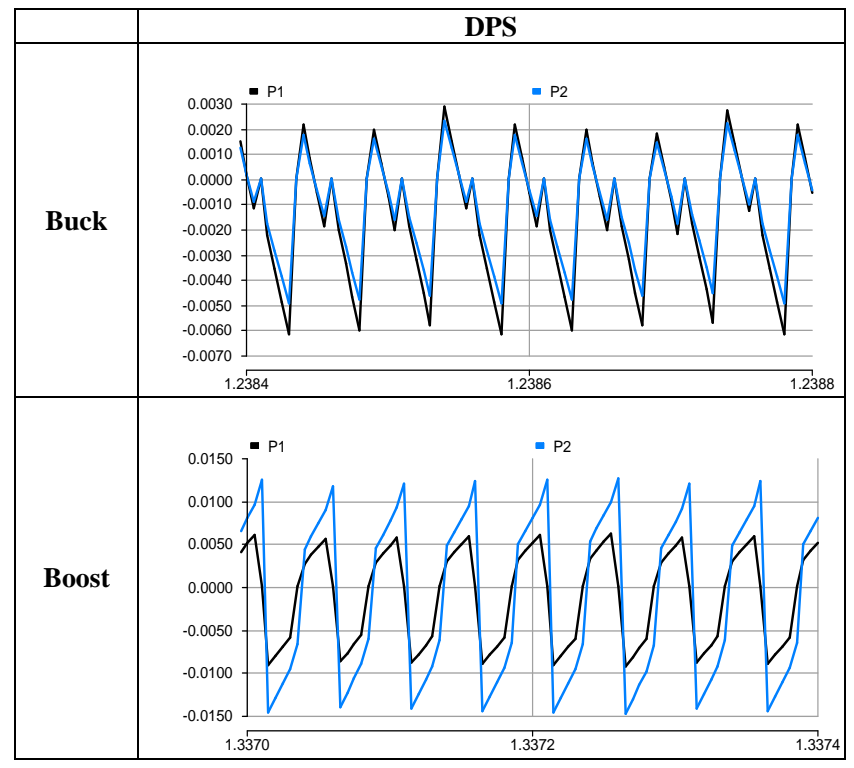

After the evaluating these waveforms, efficiencies can be expressed for buck and boost modes of the SPS, EPS and DPS in Table 9.

Table 9. Efficiencies of Phase Shift Control Methods for Buck \& Boost Modes.

\begin{tabular}{|c|c|c|c|}
\hline \multicolumn{4}{|c|}{ Efficiencies of Phase Shift Control Methods } \\
\hline & SPS & EPS & DPS \\
\hline Buck & $24.3 \%$ & $80.4 \%$ & $79.9 \%$ \\
\hline Boost & $36.4 \%$ & $62.8 \%$ & $62.6 \%$ \\
\hline
\end{tabular}

\section{Conclusions}

In conclusion, the research on an efficiency analysis of phase-shift control methods (SPS, EPS and DPS) gives us feasible results. Because the worst control method is SPS but results of EPS and DPS are similar at buck and boost modes.

But this case is correct at upside of the power waveforms only. However the underside of the power waveform of EPS buck mode has a lot of notches to reverse direction. Moreover EPS boost mode power waveform shows bigger phase shift ratio than the DPS boost mode power waveforms. In addition, not using of snubber capacitors cause to give low efficiency results. Thus, if it is wanted to be increase efficiency, snubber capacitors should be used and they are important for the single phase dual active bridge IBDC topology. This condition can be researched at future works for relative applications.

Consequently, EPS is better than SPS and it can be said that the best control method is DPS among EPS and SPS on this comparison of efficiency study paper.

\section{Acknowledgements}

The authors would like to acknowledge the TUBITAK Research Fund Number 112R028 and Scientific Research Project Unit of Cukurova University (Project. Number:FYL-2014-3276) for full support.

\section{References}

[1] C. Mi, H. Bai, C. Wang, S. Gargies "Operation, design and control of dual H-bridge-based isolated bidirectional DC-DC converter," IET Power Electron., Vol. 1, No. 4, pp. 507-517,
Mar. 2008

[2] H. Bai, C. Mi "Eliminate Reactive Power and Increase System Efficiency of Isolated Bidirectional Dual-Active-Bridge DC-DC Converters Using Novel Dual-Phase-Shift Control," IEEE Trans. Power Electron., Vol. 23, No. 6, pp. 2905-2914, Nov. 2008.

[3] Y. Xie, J. Sun, J. S. Freudenberg "Power Flow Characterization of a Bidirectional Galvanically Isolated High-Power DC/DC Converter Over a Wide Operating Range," IEEE Trans. Power Electron., Vol. 25, No. 1, pp. 54-66, Jan. 2010.

[4] G. G. Oggier, G. O. García, A. R. Oliva "Modulation Strategy to Operate the Dual Active Bridge DC-DC Converter Under Soft Switching in the Whole Operating Range," IEEE Trans. Power Electron., Vol. 26, No. 4, pp. 1228-1236, Apr. 2011.

[5] N. M. L. Tan, T. Abe, H. Akagi "Design and Performance of a Bidirectional Isolated DC-DC Converter for a Battery Energy Storage System," IEEE Trans. Power Electron., Vol. 27, No. 3, pp. 1237-1248, Mar. 2012.

[6] H. Bai, Z. Nie, C. C. Mi "Experimental Comparison of Traditional Phase-Shift, Dual-Phase-Shift and Model-BasedControl of Isolated Bidirectional DC-DC Converters," IEEE Trans. on Power Electron., Vol. 25, No. 6, pp. 1444-1449, June 2010.

[7] B. Zhao, Q. Yu, W. Sun "Extended-Phase-Shift Control of Isolated Bidirectional DC-DC Converter for Power Distribution in Microgrid," IEEE Trans. Power Electron., Vol. 27, No. 11, pp. 4667-4679, Nov. 2012.

[8] B. Zhao, Q. Song, W. Liu, W. Sun "Current-Stress-Optimized Switching Strategy of Bidirectional DC-DC Converter With Dual-Phase-Shift Control," IEEE Trans. Industrial Electron.,Vol.60,No.10, pp.4458-4487,Oct. 2013.

[9] X. Shi, J. Jiang, X. Guo "An Efficiency-Optimized Isolated Bidirectional DC-DC Converter with Extended Power Range for Energy Storage Systems in Microgrids," Energies, pp.27-44, Dec. 2012

[10] B. Zhao, Q. Song, W. Liu, Y. Sun "Overview of Dual-ActiveBridge Isolated Bidirectional DC-DC Converter for HighFrequency-Link Power Conversion System," IEEE Trans. Power Electron, Vol. 29, No.8, pp. 4091-4106, Aug. 2014.

[11] S. Inoue, H. Akagi "A Bidirectional DC-DC Converter for an Energy Storage System With Galvanic Isolation," IEEE Trans. Power Electron., Vol. 22, No. 6, pp. 2299-2306, Nov. 2007.

[12] H. Qin, J. W. Kimball "Generalized Average Modeling of Dual Active Bridge DC-DC Converter," IEEE Trans. Power Electron., Vol. 27, No. 4, pp. 2078-2083, Apr. 2012.

[13] B. Zhao, Q. Song and W. Liu "Power characterization of isolated bidirectional dual-active-bridge DC-DC converter with dualphase-shift control," IEEE Trans. Power Electron., vol. 27, no. 9, pp. 4172-4176, Sep. 2012.

[14] H. Bai and C. Mi, "Eliminate reactive power and increase system efficiency of isolated bidirectional dual-phase-shift control," IEEE Trans. Power Electron., vol. 23, no. 6, pp. 2905-2914, Nov. 2008.

[15] M. Kim, M. Rosekeit, S. K. Sul, and D. Doncker, "A dual-phaseshift control strategy for dual-active-bridge DC-DC converter in wide voltage range," in Proc. IEEE ECCE, 2011, pp. 364-371.

[16] H. Fan and H. Li, "A novel phase-shift bidirectional DC-DC converter with an extended high-efficiency range for $20 \mathrm{kVA}$ solid state transformer," in Proc. IEEE ECCE, 2010, pp. 38703876. 